\title{
The Conduction of Excitation in Mimosa.
}

THE problem of the conduction of excitation in organisms is one that concerns both plant and animal physiologists, and any advances in our understanding of conduction in either kingdom should be of common interest to all. Yet certain recent discoveries concerning excitatory conduction in plants have so far not become very widely known.

The problem comprises essentially two questions: first, what is the nature of the excitation itself ? and secondly, how is excitation at one point in an organ able to lead in turn to excitation at a neighbouring point? As to the first, there may perhaps be indications that excitation is something fundamentally similar in all protoplasm; but as to the second, it may well be that the link connecting the excitation of one point with that of the next is quite different in the case of different organs. In one case the nature of the link seems now to be well establishednamely, in the case of species of the "sensitive" genus Mimosa, on which Dr. U. Ricca ${ }^{1}$ has carried out a remarkable series of experiments.

As is well known, the spread of excitation in these plants is revealed mainly by the fall of the main petiole of the doubly compound leaf, the forward movements of the secondary petioles, and the folding together upwards in pairs of the leaflets. These movements can be brought about by injuring a leaflet, and also by inflicting cuts or burns on the main stem of the plant, which may lead to the spread of excitation along the stem and out over several leaves. It is principally on this conduction in the stem that Ricca has experimented.

The starting-point of his work is the proof that, as maintained long ago by Dutrochet, the path of conduction is the wood and not the phloem or cortex. To establish this he has made use, not of the wellknown Mimosa pudica, but of Mimosa Sepzazzinii, in which it is possible to remove completely, in a ring round the stem, the tissues external to the cambium, thus laying bare the wood.

Such ringing does not prevent the excitation from passing, as is shown by the closure of the leaflets in the leaves above the ringed zone, after a part of the stem below the ring has been stimulated by cauterisation. Conduction can therefore take place withoutcortex. Further, by removing onelongitudinal half of the stem and then, in the remaining half, prising off the extra-cambial tissues from the wood, he has been able to investigate the effects of stimulating the two separately. Stimulation of the strip of wood leads to movements in the leaves above, even after the pith has been scraped away, whereas stimulation of the strip of phloem and cortex does not. Since the latter are known not to be insensitive to stimulus, it follows that they must be unable alone to conduct the excitation effectively.

Next Ricca confirms the fact, already known, that conduction can pass through a zone of the stem that has been completely killed by heat, and he also shows that even when a zone of $4-5 \mathrm{~cm}$; is maintained at a temperature above $150^{\circ} \mathrm{F}$. this does not prevent the supply of water to the leaves above, nor the conduction of excitation. Going further, he divides the stem transversely and inserts the cut ends into the expanded ends of a narrow glass tube $8 \mathrm{~cm}$. long and I mm. in diameter. An earlier experiment with a wider tube (I9I6," "a," p. 94) is less convincing.

1 Ricca, U., "Soluzione d' un problema di fisiologia," Nuovo Giorn. Bot. Ital. 23, x916, " a."

"Solution d'un problème de physiologie," Archives italiennes de Biologie, 65, 1916, "b."

NO. 278 I, VOL. III I]
Cauterisation of the stem below the tube was followed by closure of the leaflets above it; and if the stimulus was strong, a greenish substance was seen to issue from the lower cut end, and slowly to spread up the tube. The time taken by the coloration to spread agreed roughly with the time apparently taken by the excitation to pass the tube (see schedules, loc. cit., p. II9sq.)

Already these results suggested that conduction takes place by the transference of a soluble stimulating substance excreted by the stimulated cells; for increase of permeability and excretion of liquid is known to accompany excitation in Mimosa and other plants. The final experiment in confirmation of this was the extraction of the substance by preparing in a small quantity of water a large number of transverse sections of stem. Other cut branches were then placed with their cut ends in the liquid thus obtained, and thereby excitation was found to be set up in them and to spread gradually up from the cut end towards the apex, as shown by the successive movements of their leaves.

It seems clear then that conduction both in the glass tube and in the wood of the plant must be brought about by the movement of a stimulating substance with the water current. It cannot be due to pressure changes; first, because it is too slow (in one case $55 \mathrm{~cm}$. in $1 \frac{1}{4}$ hours: average values for $M$. pudica are 8-15 mm. per sec. in the petiole and $2-3 \mathrm{~mm}$. per sec. in the stem); and secondly, artificial changes in pressure of the water-supply to cut branches were not found to result in stimulation.

In agreement with this, factors increasing transpiration and so accelerating the ascent of water in the stem were found to increase the rate of conduction. Still; it may remain uncertain whether movements of the water current alone can account for all cases of conduction in these plants, particularly for basipetal conduction in the leaves. In Mimosa Spezazzinii this takes place only with difficulty, and Ricca considers it due to the excretion of liquid from the stimulated region, which is then sucked away in both directions by neighbouring unstimulated tissues. In Mimosa pudica basipetal conduction takes place rapidly and easily. Possibly the activity of other living tissues along the conducting zone may in some cases be involved, even if it is not necessary for conduction in the stem. It is also desirable that the results should be confirmed by other workers in warm countries.

Comparison may be made with the conduction of excitation in the cotyledon of a grass seedling, which also seems to involve a stimulating substance. In this organ, various stimuli, striking on the tip alone, bring about a responsive curvature in the elongating region below. The excitation conducted from tip to responding region can pass through a layer of gelatin, after the tip has been cut off and stuck on again. ${ }^{2}$ It appears that Stark (loc. cit.) has extracted the stimulating substance concerned. An excitatory process capable of passing through gelatin has also been found by the present writer in roots.

But in these cases the mechanism of conduction in the tissues is still obscure, and probably different from that found in Mimosa. It appears that conduction may here take place in parenchymatous tissues, and it is checked by local application of anæsthetics and other physiological agents.

R. SNow.

2 Boysen-Jensen. Ber. d. D. Bot. Ges., 3i, p. 559 . I9r3. Paal, Jahrb. f. wiss. Bot. 58,-1918. Stark, Jahib. f. wiss. Bot. 60 , I921. 